\title{
Fall Prevention in a Primary Care Setting
}

The Effects of a Targeted Complex Exercise Intervention in a Cluster Randomized Trial

Monika Siegrist, Ellen Freiberger, Barbara Geilhof, Johannes Sall, Christian Hentschke, Peter Landendoerfer, Klaus Linde, Martin Halle, Wolfgang A. Blank

\section{SUMMARY}

Background: Falls and fall-related injuries are common in community-dwelling elderly people. Effective multifactorial fall prevention programs in the primary care setting may be a promising approach to reduce the incidence rate of falls.

Methods: In a cluster randomized trial in 33 general practices 378 people living independently and at high risk of falling (65 to 94 years old; 285 women) were allocated to either a 16 week exercise-based fall prevention program including muscle strengthening and challenging balance training exercises, combined with a 12 week home-based exercise program (222 participants), or to usual care (156 participants). The main outcome was number of falls over a period of 12 months. Secondary outcomes were the number of fall-related injuries, physical function (Timed-Up-and-Go-Test, TUG, Chair-Stand-Test, CST, modified Romberg Test), and fear of falling.

Results: In the intervention group ( $n=222$ patients in 17 general practices) 291 falls occurred, compared to 367 falls in the usual care group $(n=156$ patients in 16 general practices). We observed a lower incidence rate for falls in the intervention group (incidence rate ratio/IRR: $0.54 ; 95 \%$ confidence interval $(\mathrm{Cl})$ : [0.35; 0.84], $p=0.007$ ) and for fall-related injuries (IRR: 0.66; [0.42; 0.94], $\mathrm{p}=0.033$ ). Additionally, patients in the intervention group showed significant improvements in secondary endpoints (TUG: $-2.39 \mathrm{~s},[-3.91 ;-0.87], \mathrm{p}=0.014$; mRomberg: $1.70 \mathrm{~s},[0.35 ; 3.04], \mathrm{p}=0.037$; fear of falling: -2.28 points, $[-3.87$; $-0.69], p=0.022$ ) compared to usual care.

Conclusion: A complex falls prevention program in a primary care setting was effective in reducing falls and fall-related injuries in community dwelling older adults at risk.

\section{Cite this as:}

Siegrist M, Freiberger E, Geilhof B, Salb J, Hentschke C, Landendoerfer P, Linde $\mathrm{K}$, Halle M, Blank WA: Fall prevention in a primary care settingthe effects of a targeted complex exercise intervention in a cluster randomized trial. Dtsch Arztebl Int 2016; 113: 365-72. DOI: 10.3238/arztebl.2016.0365

Department of Prevention, Rehabilitation and Sports Medicine, Technische Universität München, Munich, Germany: Dr. phil. Siegrist, B. Geilhof, Prof. Dr. med. Halle

Institute for Biomedicine of Aging, Universität Erlangen-Nürnberg, Nürnberg, Germany:

PD Dr. phil. Freiberger, J. Salb

Institute of Sport Science and Sport, Universität Erlangen-Nürnberg, Nürnberg, Germany: C. Hentschke

Institute of General Practice, Technische Universität München, Munich, Germany: Dr. med. Landendoerfer; Prof. Dr. med. Linde, Dr. med. Blank

DZHK (German Centre for Cardiovascular Research), partner site Munich Heart Alliance, Munich, Germany and Else Kröner-Fresenius-Zentrum, Klinikum rechts der Isar, Technische Universität München, Munich, Germany: Prof. Dr. med. Halle alls and fall-related injuries are common in community-dwelling older people and increase exponentially with age. Approximately $30 \%$ of people over 65 years report at least one fall each year $(1,2)$.

The most common fall-related injury resulting in admission to hospital is a fracture (89\%) (3). Fractures are often followed by

- permanently reduced mobility,

- admission to long-term care,

- increased health costs and

- excess mortality (3-5).

About 40 to $70 \%$ of recent fallers have fear of falling $(6,7)$, which leads to activity restriction, social isolation and worsening of quality of life. Despite these serious consequences older people are often not aware of being at risk of falling $(8,9)$.

Due to the demographic changes and high prevalence of falls in the elderly, the necessity of systematic regular fall risk assessments and subsequent interventions in this group seems mandatory. General practitioners (GPs) see these patients on a regular basis and can identify patients at risk for falls.

Therefore, an annual screening has been recommended by the Prevention of Falls Network Europe (ProFANE) group (10). Patients identified should be offered an effective exercise program $(8,11)$. The recently published Cochrane review confirmed that the use of group- and home-based exercise programs reduces the number of falls in older people living in the community (12). In agreement with other reviews (13) effective exercise intervention programs should include balance training and progressive strength training (12-14).

Although fall prevention programs have many proven benefits, few trials have imbedded exercisebased fall prevention programs into the setting of general medical practice (15-17). The primary aim of the PreFalls (Prevent Falls) trial was to investigate, whether the implementation of an exercise-based fall prevention program in the German primary care setting (general practitioners), consisting of 16 weeks of group exercise in combination with an individualized homebased training program, can significantly reduce the number of falls per individual in community-dwelling older people at high risk of falls compared to those re- 
ceiving usual care over a period of one year. Secondary aims were to explore the incidence of fall-related injuries and the effects of the training program on physical function as well as on fear of falling.

\section{Methods}

\section{Participants and Recruitment}

The study protocol has been previously published (18). In brief, for the cluster-randomized two level trial (general practices and patients) general practitioners in southern Germany were invited (Figure 1). The general practitioners included community-dwelling senior citizens aged $\geq 65$ years with increased physical fall risk into the trial. Increased fall risk was defined as one or more falls in the past 12 months, low physical function (Timed-up-and-Go-Test or Chair-Stand-Test $>10$ seconds [19-21]) or subjective or objective balance deficits or fear of falling. At least one criterion was necessary for inclusion into the study. Those individuals who did not live independently or suffered from physical or mental restrictions that interfered with the assessment of physical fall risk or participation in an exercise program were excluded.

The study protocol was approved by the ethics committee of the University Hospital, Klinikum rechts der Isar, Technische Universität München (number 2386/09). All participants gave written informed consent (Figure 1).

\section{Measurements}

Demographic data, body-mass-index, fall risk assessment, comorbidities and medications were assessed by trained assistants of the general practitioners who were otherwise not involved in the study design or in the exercise program.

The primary outcome of the fall prevention program was to reduce the number of falls. As reported in our protocol (18), falls were monitored by patients over the full study period with a daily fall calendar. Since some people do not distinguish between tripping (no injury) or falling (with injury) in everyday language, both terms were explicitely inquired. For each day the patients marked whether they had fallen or tripped. The monthly calendar was sent back to the study coordinators during the first week of the following month in a prepaid envelope. When a fall was reported, detailed information was obtained through structured telephone interviews by trained assistants in the first two weeks of the following month. In this study a fall was defined as 'an unexpected event in which the participant comes to rest on the ground, floor, or lower level' (10).

Secondary outcome measures were number of fallers as well as number of fall-related injuries, improvements in physical function and fear of falling. Physical function was assessed using the 'Timed-Up-and-GoTest' (TUG), (20, 22), strength with the 'Chair-StandTest' (CST) and balance with the modified Romberg Test (mRomberg) (23) as described previously (18). Fear of falling was assessed with the German version of the Falls Efficacy Scale-International (FES-I) (24)
(eBox1). Physical function and fear of falling were assessed by the general practitioners at baseline and after 12 months.

\section{Randomization}

A biostatistician not involved in the study randomized general practices into the intervention or control group by using computer-generated random numbers. After the randomization, the general practitioners enrolled patients for the study according to the inclusion and exclusion criteria (18). Masking of participants was not feasible because half of the patients were allocated to usual care and not enrolled in any exercise interventions.

\section{Intervention}

Physicians and one staff member from each participating general practice in both the intervention and the usual care group were trained in workshops lasting 3.5 hours including general information about falls and fall risk assessments. Information on the exercise intervention has been published in depth (25). The intervention program on the patients' level consisted of a 16 week supervised exercise training program (1 hour/week) with strength and power training, challenging balance and gait training with increasing levels of difficulty, behavioral aspects, a self-management program and perceptual and functional training conducted by a fall prevention instructor (physiotherapist or sports scientist). This program was evaluated in former fall prevention research (26) and only slightly modified (25) (eTable 1). The usual care group (CG) received no structured treatment to prevent falls due to a lack of guidelines for GPs apart from individual GPs experience (18).

\section{Sample Size Calculation}

Sample size calculation was performed using the IcebergSim software (version: Beta 3.06, Bergel 2005-2006), which allows to consider intracluster correlation, an important issue in cluster randomized trials. Calculations were based on assumptions regarding the proportion of individuals with at least one fall during a 12-month follow up period. Based on the trial by Spice et al. (27) an intra-cluster correlation coefficient of 0.02 was assumed and a cluster size of ten was considered to be realistic. Therefore, about 40 clusters (382 individuals in all) were planned to be included to detect a clinically relevant reduction from $33 \%$ to $20 \%$ with $80 \%$ power at two-sided level of significance of $5 \%$.

\section{Statistical Analysis}

To investigate the difference in the cumulated number of falls per individual within 12 months (primary outcome) in the intervention versus the control group, the incidence rate ratio was estimated. To account for the hierarchical structure in the chosen cluster randomized study design with individuals nested in general practices, a generalized linear mixed effects Poisson model was used (eBox 2) (28). Primary endpoint was 
Recruitment of general practices

a) via postal service and telephone call - 896 general practitioners

b) via local peer groups and quality circles - 52 general practitioners

c) via newspaper and medical journals, homepage

40 general practices agreed to take part

\begin{tabular}{|l|}
\hline Cluster-randomization of general practices \\
13 trainings for 40 general practitioners and staff \\
Computer-based randomization in 20 intervention and 20 control general \\
practices \\
Drop-0ut \\
3 general practices of the intervention group and 4 general practices of \\
the control group
\end{tabular}

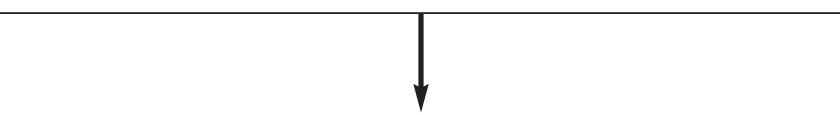

\footnotetext{
Recruitment of participants in $\mathbf{3 3}$ general practices

Baseline Data from 378 patients

222 patients in the intervention group ( $n=5-32$ patients

156 patients in the control group ( $n=4-23$ patients)

( $n=$ number of recruited patients per general practice)
}

Participation in the exercise program

12 patients never took part

29 patients took part 1 to 9 times

181 patients participated more than 10 times (out of 16)

\begin{tabular}{|l|}
\hline Lost to follow-up \\
Intervention group: 38 patients $(17.1 \%)$ \\
Refused further participation $(n=3)$ \\
Death $(n=8)$ \\
Poor health $(n=10)$ \\
Unknown reason $(n=6)$ \\
Dementia $(n=1)$, \\
Admission to a residential care home for elderly $(n=1)$ \\
Orthopedic problems $(n=5)$ \\
Cancer or heart problems $(n=2)$ \\
Change of residence $(n=2)$
\end{tabular}

\begin{tabular}{|l|}
\hline Intervention group \\
Analysis primary endpoint: 222 patients \\
Fall risk assessment after 12 months: 184 patients \\
\hline
\end{tabular}

Lost to follow-up
Control group: 40 patients $(25.6 \%)$
Refused further participation $(n=8)$
Death $(n=10)$
Poor health $(n=7)$
Unknown reason $(n=3)$
Dementia $(n=4)$
Admission to a residential care home for elderly $(n=5)$
Orthopedic problems $(n=0)$
Cancer or heart problems $(n=2)$
Change of residence $(n=1)$
\[ \]
Control group
Analysis primary endpoint: 156 patients
Fall risk assessment after 12 months: 116 patients




\section{TABLE 1}

Baseline data

\begin{tabular}{|c|c|c|c|c|c|}
\hline \multicolumn{2}{|l|}{ Characteristics } & \multicolumn{2}{|c|}{ Intervention group } & \multicolumn{2}{|c|}{ Control group } \\
\hline \multicolumn{6}{|l|}{ Demographic data } \\
\hline \multicolumn{2}{|l|}{ Sex (male/female) } & \multicolumn{2}{|l|}{$50 / 172$} & $43 / 113$ & 0.263 \\
\hline Age (years) & $N=222$ & $78 \pm 6$ & $N=156$ & $78 \pm 6$ & 0.600 \\
\hline BMI $\left(\mathrm{kg} / \mathrm{m}^{2}\right)$ & $N=222$ & $27 \pm 5$ & $N=156$ & $27 \pm 5$ & 0.574 \\
\hline Living alone, N (\%) & $N=222$ & $98(44.0)$ & $N=156$ & $60(38.5)$ & 0.197 \\
\hline \multicolumn{6}{|l|}{ Physical function } \\
\hline \multirow[t]{2}{*}{ TUG (s) } & \multirow[t]{2}{*}{$N=222$} & $13.0 \pm 5.5$ & \multirow[t]{2}{*}{$N=155$} & $16.2 \pm 8.4$ & \multirow[t]{2}{*}{$<0.001$} \\
\hline & & $12.0(5,0-40.8)$ & & $14.0(6.0-45.0)$ & \\
\hline \multirow[t]{2}{*}{ CST (s) } & \multirow[t]{2}{*}{$N=214$} & $17,4 \pm 9.3$ & \multirow[t]{2}{*}{$N=137$} & $19.4 \pm 10.1$ & \multirow[t]{2}{*}{0.024} \\
\hline & & $15.0(7,0-90.0)$ & & $16.7(7.6-68.0)$ & \\
\hline \multirow[t]{2}{*}{ mRomberg (sum) } & \multirow[t]{2}{*}{$N=221$} & $25,4 \pm 6,1$ & \multirow[t]{2}{*}{$N=153$} & $24.0 \pm 7.9$ & \multirow[t]{2}{*}{0.071} \\
\hline & & $30.0(2,0-30.0)$ & & $30.0(2.0-30.0)$ & \\
\hline \multirow[t]{2}{*}{ FES-I (sum score) } & \multirow[t]{2}{*}{$N=203$} & $25,2 \pm 8.2$ & \multirow[t]{2}{*}{$N=149$} & $27.4 \pm 9.8$ & \multirow[t]{2}{*}{0.010} \\
\hline & & $23.0(16,0-58.0)$ & & $25.0(16.0-58.0)$ & \\
\hline \multicolumn{2}{|l|}{ Comorbidities } & \multicolumn{2}{|l|}{$\mathrm{N}(\%)$} & \multicolumn{2}{|l|}{$\mathrm{N}(\%)$} \\
\hline Fall last year & $N=218$ & $118(54.1)$ & $N=156$ & $80(51.3)$ & 0.587 \\
\hline Dizziness & $N=218$ & $111(50.9)$ & $N=150$ & $92(61.3)$ & 0.048 \\
\hline Parkinson's disease & $N=220$ & $7(3.2)$ & $N=146$ & $8(5.5)$ & 0.278 \\
\hline Stroke & $N=220$ & $26(11.8)$ & $N=150$ & $18(12.0)$ & 0.958 \\
\hline Osteoporosis & $N=211$ & 74 (35.1) & $N=148$ & $45(30.4)$ & 0.355 \\
\hline Depression & $N=217$ & $45(20.7)$ & $N=145$ & $34(23.4)$ & 0.541 \\
\hline Visual impairment & $N=213$ & $92(43.2)$ & $N=144$ & $60(41.7)$ & 0.775 \\
\hline Type-2-Diabetes & $N=218$ & $58(26.6)$ & $N=149$ & $52(34.9)$ & 0.089 \\
\hline High blood pressure & $N=218$ & $148(67.9)$ & $N=149$ & $96(64.4)$ & 0.490 \\
\hline Body sway & $N=213$ & $91(42.7)$ & $N=148$ & $65(43.9)$ & 0.822 \\
\hline Paralysis & $N=217$ & $7(3.2)$ & $N=147$ & $6(4.1)$ & 0.666 \\
\hline Neurological deficits & $N=212$ & $46(21.7)$ & $N=140$ & $22(15.7)$ & 0.164 \\
\hline Knee pain & $N=216$ & $125(57.9)$ & $N=151$ & $87(57.6)$ & 0.961 \\
\hline Hip pain & $N=215$ & $87(40.6)$ & $N=149$ & $72(48.3)$ & 0.137 \\
\hline ADL deficits & $N=214$ & $92(43.0)$ & $N=145$ & $58(40.0)$ & 0.573 \\
\hline Walking aid & $N=216$ & $73(33.8)$ & $N=150$ & $69(46.0)$ & 0.018 \\
\hline$>4$ medications & $N=206$ & $123(59.7)$ & $N=128$ & $87(68.0)$ & 0.129 \\
\hline
\end{tabular}

Data are presented as mean \pm standard deviation and median (min-max), respectively;

ADL, Activity of daily living; BMI, Body-mass-index; CST, Chair Stand Test; FES-I, Falls Efficacy Scale - International; mRomberg, modified Romberg Test; TUG, Timed-Up-and-Go-Test; p-values for baseline differences (t-test for normal distributed data, Mann-Whitney U-test for skewed data) 
Incidence of fall events during the 12-month period in the intervention group and the control group

\begin{tabular}{l|c|c|c|c} 
& $\begin{array}{c}\text { Intervention group } \\
(\mathrm{N}=222)\end{array}$ & $\begin{array}{c}\text { Control group } \\
(\mathrm{N}=156)\end{array}$ & IRR/OR [95\% Cl] & $\mathrm{p}$-value \\
\hline Falls, $\mathrm{n}($ rate $)$ & $291(1.3)$ & $367(2.4)$ & IRR: $0.54[0.35 ; 0.84])$ & 0.007 \\
\hline Faller, $\mathrm{n}(\%)$ & $73(32.8)$ & $70(44.9)$ & OR: $0.52[0.29 ; 0.91]$ & 0.021 \\
\hline Fall-related injuries, $\mathrm{n}(\%)$ & $63(28.4)$ & $59(37.8)$ & IRR: $0.66[0.42 ; 0.94]$ & 0.033 \\
\hline
\end{tabular}

Faller; person with more than one fall per year or at least one injurious fall

$\mathrm{Cl}$, Confidence interval; IRR, Incidence Rate Ratio; OR, Odds Ratio; Intracluster-Correlation-Coefficient = 0.165

tested confirmatory, secondary endpoints were tested without adjustment for multiple testing. The relative risk in intervention versus control group for being a faller or an injurious faller was calculated by two generalized hierarchical linear logistic regression models. Per considered secondary outcome measure a three level linear mixed effects model was used.

\section{Results}

40 general practices took part in the study. Seven general practices dropped out after randomization and before recruiting patients. In 33 practices a total of 378 patients (65 to 94 years, mean age $78.1 \pm 5.9$ years, 285 women) were included. Recruiting time was July 2009 to March 2010. Reasons for loss to follow-up ( $n=78$ patients) were documented (Figure 1).

The fall prevention program was organized in cooperation with the participating general practices in the living environment of the patients. In each training group four to 12 participants took part. In total, 181 of the patients (82\%) participated in more than ten training sessions. 46\% of the patients (101 of 222 participants) performed the home exercise program ten times or more (average 6.7 times). No adverse effects were observed during the exercise program (Figure 1).

More than $50 \%$ of all patients reported at least one fall in the year before the study. Further comorbidities are presented in Table 1.

During the 12 months, 291 falls occurred in the IG $(n=222)$ compared to 367 falls in the CG $(n=156)$. In the IG, 58.1\% $(n=129)$ of the patients reported no fall in the 12 months compared to $50.6 \%(n=79)$ in the CG. The linear mixed model showed a significant lower incidence rate (IRR) for falls (IRR: 0.54 ; 95\% confidence interval (CI): [0.35; 0.84]; $\mathrm{p}=0.007$ ) in the IG compared to the CG (Table 2). According to the changes in the updated guideline of the American Geriatrics Society and the British Geriatrics Society (29) a faller was defined as a person, who reported more than one fall during the 12-months period or had at least one fall with a fall-related injury. 70 out of 156 patients in the CG were fallers (44.9\%) compared to 73 out of 222 (32.8\%) patients in the IG. The odds ratio to be a faller was significantly lower in the IG compared to the CG (OR: 0.52, [0.29, 0.91], $\mathrm{p}=0.021$ ). During the
12 months, out of 658 falls, 479 telephone interviews provided further information on fall-related injuries. In the CG 59 of 156 patients reported at least one fallrelated injury compared to 63 of 222 patients in the IG. The incidence rate for fall related injuries was significantly lower in the IG compared to the CG (IRR: 0.66; [0.42; 0.94]; $p=0.033$ ). After adjustment for baseline differences in physical function the IRR for falls was 0.68 [0.42; 1.22] and for fall related-injuries 0.79 [0.49; 1.33]. Sensitivity analysis for the parameter "faller" was statistically not feasible. In this sensitivity analysis, only data from 350 of 378 patients could be included due to missing values in physical function.

Patients in the IG showed small improvements in the Timed-Up-and-Go-Test, whereas patients in the CG required significantly more time $(p=0.014)$. No significant difference in time needed for the Chair Stand Test was found between IG and CG $(p=0.466)$. Nevertheless, after 12 months in the CG 20 out of 114 patients were not able to stand up from a chair five times compared to 12 of 184 patients in the IG. The balance performance in the mRomberg test significantly increased in the IG compared to the CG $(p=0.037)$ (Table 3). At the beginning of the intervention, 100 of 179 patients in the IG succeeded in all balance tests compared to 64 of 105 patients in the CG. After 12 months, 115 of 179 patients of the patients in the IG and 54 of 105 patients in the CG performed all balance tests successfully. The fear of falling was significantly reduced in the IG ( $\mathrm{p}=0.022$, Table 3$)$.

\section{Discussion}

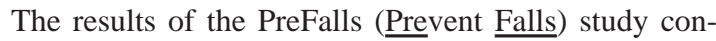
firmed that the implementation of an exercise-based fall prevention program in the primary care setting (general practitioners), consisting of 16 weeks of group exercise in combination with an individualized homebased training program, can significantly reduce the number of falls per individual, the number of fallers and the incidence rate of fall-related injuries in community-dwelling older people with high risk of falls compared to those in usual care.

During the 12-month trial period, 291 falls occurred in the intervention group and 367 falls were reported in the control group with a significantly lower incidence 
Fall Risk Assessment (Physical Function) and Fear of Falling

\begin{tabular}{|c|c|c|c|c|c|c|}
\hline & $\begin{array}{l}\text { Intervention } \\
\text { group } \\
\text { at baseline }\end{array}$ & $\begin{array}{l}\text { Intervention } \\
\text { group } \\
\text { at } 12 \text { months }\end{array}$ & $\begin{array}{l}\text { Control } \\
\text { group } \\
\text { at baseline }\end{array}$ & $\begin{array}{l}\text { Control } \\
\text { group } \\
\text { at } 12 \text { months }\end{array}$ & $\begin{array}{c}\text { Difference } \\
\text { between groups } \\
{[95 \% \mathrm{Cl}]}\end{array}$ & p-value \\
\hline \multirow{3}{*}{$\begin{array}{l}\text { TUG } \\
\text { (seconds) }\end{array}$} & $N=222$ & $N=181$ & $N=155$ & $N=114$ & & \\
\hline & $13.0 \pm 5.5$ & $12.1 \pm 5.3$ & $16.2 \pm 8.4$ & $17.7 \pm 12.6$ & $\begin{array}{c}-2.39 \\
{[-3.91 ;-0.87]}\end{array}$ & 0.014 \\
\hline & $\begin{array}{c}12.0 \\
(5.5-40.8)\end{array}$ & $\begin{array}{c}11.0 \\
(4.0-42.4)\end{array}$ & $\begin{array}{c}14.0 \\
(6.0-45.0)\end{array}$ & $\begin{array}{c}13.5 \\
(5.0-92.0)\end{array}$ & & \\
\hline \multirow{3}{*}{$\begin{array}{l}\text { CST } \\
\text { (seconds) }\end{array}$} & $N=214$ & $N=172$ & $N=137$ & $N=94$ & & \\
\hline & $17.4 \pm 9.3$ & $14.8 \pm 6.4$ & $19.4 \pm 10.1$ & $17.1 \pm 7.9$ & $\begin{array}{c}-0.73 \\
{[-2.60 ; 1.14]}\end{array}$ & 0.466 \\
\hline & $\begin{array}{c}15.0 \\
(7.0-90.0)\end{array}$ & $\begin{array}{c}13.4 \\
(6.8-60.0)\end{array}$ & $\begin{array}{c}16.7 \\
(7.6-68.0)\end{array}$ & $\begin{array}{c}15.0 \\
(8.0-49.0)\end{array}$ & & \\
\hline \multirow{3}{*}{$\begin{array}{l}\text { mRomberg } \\
\text { (seconds) }\end{array}$} & $N=222$ & $N=181$ & $N=153$ & $N=107$ & & \\
\hline & $25.3 \pm 6.2$ & $26.7 \pm 5.3$ & $24.0 \pm 7.9$ & $24.1 \pm 7.5$ & $\begin{array}{c}1.70 \\
{[0.35 ; 3.04]}\end{array}$ & 0.037 \\
\hline & $\begin{array}{c}30.0 \\
(2.0-30.0)\end{array}$ & $\begin{array}{c}30.0 \\
(10.0-30.0)\end{array}$ & $\begin{array}{c}30.0 \\
(2.0-30.0)\end{array}$ & $\begin{array}{c}30.0 \\
(7.0-30.0)\end{array}$ & & \\
\hline \multirow{3}{*}{$\begin{array}{l}\text { FES-I } \\
\text { (points) }\end{array}$} & $N=203$ & $N=167$ & $N=149$ & $N=108$ & & \\
\hline & $25.2 \pm 8.2$ & $23.4 \pm 7.4$ & $27.4 \pm 9.8$ & $27.5 \pm 10.3$ & $\begin{array}{c}-2.28 \\
[-3.87 ;-0.69])\end{array}$ & 0.022 \\
\hline & $\begin{array}{c}23.0 \\
(16.0-58.0)\end{array}$ & $\begin{array}{c}21.0 \\
(16.0-49.0)\end{array}$ & $\begin{array}{c}25.0 \\
(16.0-58.0)\end{array}$ & $\begin{array}{c}25.0 \\
(16.0-54.0)\end{array}$ & & \\
\hline
\end{tabular}

Data are presented as mean \pm standard deviation and median (min-max)

Cl: Confidence interval; CST: Chair Stand Test; mRomberg: modified Romberg Test; TUG, Timed-Up-and-Go-Test

rate of falls in the IG compared to the CG and a significantly reduced odds ratio to be a faller. The benefits of PreFalls were more pronounced than the results of a 12-month fall prevention program earlier described by Lord et al., who reported 31\% fewer falls in the intervention group. Nevertheless the adherence rate in that program was only moderate (29). A systematic review by Sherrington showed greater effects in intervention programs that focused on challenging balance exercise, individual targeted exercise (regarding intensity and type of exercise) and less walking (30). These aspects were included into the study design of PreFalls. Additionally, best practice recommendations for those at high risk for falls (small group sizes and closer supervision) were included (31). The results confirm that general practices are a promising setting in fall prevention in older people. Primary care physicians have direct access to elderly with high risk of falling, providing contact to effective fall prevention for their patients. This strategy adds to the Cochrane review recommendation (12).

Additionally, patients in the IG showed significantly better functional mobility assessed by the TUG compared to the CG. A ceiling effect may be seen in CST and in mRomberg. In CST, patients with lower baseline levels may be unable to perform five chair stands ups in the follow-up (32).

The high impact of physical performance on fall risk has been established during recent years (12). Therefore, in addition to the improvements in the primary endpoint, the results in physical function confirm the positive effects of the conducted fall prevention program.

Concerns about falling are common in about $43 \%$ of community-living older people (6) and $16 \%$ of fallers reported to reduce their usual activity because of fear of falling (33). In our study fear of falling was significantly reduced after 12 months in the IG. (6).

\section{Limitations}

In general, studies in a primary care setting have an impact on study design, but significantly improve applicability into the general care of patients. Therefore, in order to implement an exercise program for a wide range of older people with high risk of falling, we included the "usual older patient" in a German general practice without further exclusion criteria. We cannot exclude that the physicians in the intervention group included patients with better physical shape in contrast to the control group. Masking of participants was not 


\section{KEY MESSAGES}

- Falls and fall-related injuries are common in communitydwelling older people and increase exponentially with age.

- General practitioners see these patients on a regular basis and can identify patients at risk for falls.

- Patients identified at high risk of falling should be offered an effective exercise program including balance and progressive strength training.

- An exercise-based fall prevention program can significantly reduce the number of falls per individual, the number of fallers and the incidence rate of fall-related injuries in community-dwelling older people with high risk of falls.

feasible because half of the patients were allocated to usual care and, therefore were not enrolled in any exercise intervention. Fall risk assessment was examined by trained staff members of the general practices otherwise not involved in the study.

\section{Conclusion}

This study shows that the general practice is an ideal setting for an exercise-based fall prevention program to prevent falls in community-dwelling elderly at risk.

\section{Conflict of interest statement}

The authors declare that no conflict of interest exists.

Funding: Bavarian State Ministry of the Environment and Public Health, Munich, Germany (Gesund.Leben.Bayern.) (LP 00110, Pr.Nr. 09-10).

Manuscript received on 270ctober 2015, revised version accepted on 1February 2016

\section{REFERENCES}

1. Speechley M, Tinetti M: Falls and injuries in frail and vigorous community elderly persons. J Am Geriatr Soc 1991; 39: 46-52.

2. Tinetti ME, Speechley M, Ginter SF: Risk factors for falls among elderly persons living in the community. N Engl J Med 1988; 319: 1701-7.

3. Peel NM, Kassulke DJ, McClure RJ: Population based study of hospitalised fall related injuries in older people. Inj Prev 2002; 8: 280-3.

4. Ensrud KE, Ewing SK, Taylor BC, et al.: Frailty and risk of falls, fracture, and mortality in older women: the study of osteoporotic fractures. J Gerontol A Biol Sci Med Sci 2007; 62: 744-51.

5. Icks A, Haastert B, Wildner M, Becker C, Meyer G: Trend of hip fracture incidence in Germany 1995-2004: a population-based study. Osteoporos Int 2008; 19: 1139-45.

6. Tinetti ME, Mendes de Leon CF, Doucette JT, Baker DI: Fear of falling and fall-related efficacy in relationship to functioning among community-living elders. J Gerontol 1994; 49: M140-7.

7. Zijlstra GA, van Haastregt JC, van Eijk JT, et al.: Prevalence and correlates of fear of falling, and associated avoidance of activity in the general population of community-living older people. Age Ageing 2007; 36: 304-9.
8. Yardley L, Donovan-Hall M, Francis K, Todd C. Attitudes and beliefs that predict older people's intention to undertake strength and balance training. J Gerontol B Psychol Sci Soc Sci 2007; 62: 119-25

9. Yardley L, Donovan-Hall M, Francis K, Todd C: Older people's views of advice about falls prevention: a qualitative study. Health Educ Res 2006; 21: 508-17.

10. Lamb SE, Jorstad-Stein EC, Hauer K, Becker C: Development of a common outcome data set for fall injury prevention trials: the Prevention of Falls Network Europe consensus. J Am Geriatr Soc 2005; 53: 1618-22.

11. American Geriatrics Society, British Geriatrics Society, American Academy of Orthopaedic Surgeons: Panel on falls prevention. Guideline for the prevention of falls in older persons. J Am Geriatr Soc 2001; 49: 664-72

12. Gillespie LD, Robertson MC, Gillespie WJ, et al.: Interventions for preventing falls in older people living in the community. Cochrane Database Syst Rev 2012; 9: CD007146.

13. Sherrington C, Lord SR, Close JC, et al.: Development of a tool for prediction of falls in rehabilitation settings (Predict_FIRST): a prospective cohort study. J Rehabil Med 2010; 42: 482-8.

14. Panel on Prevention of Falls in Older Persons American Geriatrics Society and British Geriatrics Society: Summary of the Updated American Geriatrics Society/British Geriatrics Society clinical practice guideline for prevention of falls in older persons. J Am Geriatr Soc 2011; 59: 148-57.

15. Gardner MM, Phty M, Robertson MC, McGee R, Campbell AJ: Application of a falls prevention program for older people to primary health care practice. Prev Med 2002; 34: 546-53.

16. Gates S, Fisher JD, Cooke MW, Carter YH, Lamb SE: Multifactorial assessment and targeted intervention for preventing falls and injuries among older people in community and emergency care settings: systematic review and meta-analysis. BMJ 2008; 336: 130-3.

17. Rubenstein LZ, Alessi CA, Josephson KR, et al.: A randomized trial of a screening, case finding, and referral system for older veterans in primary care. J Am Geriatr Soc 2007; 55: 166-74.

18. Blank WA, Freiberger $E$, Siegrist M, et al.: An interdisciplinary intervention to prevent falls in community-dwelling elderly persons: protocol of a cluster-randomized trial [PreFalls]. BMC Geriatr 2011; $11: 7$.

19. Guralnik JM, Simonsick EM, Ferrucci L, et al.: A short physical performance battery assessing lower extremity function: association with self-reported disability and prediction of mortality and nursing home admission. J Gerontol 1994; 49: M85-94.

20. Podsiadlo D, Richardson S: The timed „Up \& Go": a test of basic functional mobility for frail elderly persons. J Am Geriatr Soc 1991; 39: $142-8$.

21. Shumway-Cook A, Baldwin M, Polissar NL, Gruber W: Predicting the probability for falls in community-dwelling older adults. Phys Ther 1997; 77: 812-9.

22. Shumway-Cook A, Brauer S, Woollacott M: Predicting the probability for falls in community-dwelling older adults using the Timed Up \& Go Test. Phys Ther 2000; 80: 896-903.

23. Guralnik JM, Ferrucci L, Simonsick EM, Salive ME, Wallace RB: Lower-extremity function in persons over the age of 70 years as a predictor of subsequent disability. N Engl J Med 1995; 332: 556-61.

24. Kempen Gl, Todd CJ, van Haastregt JC, et al.: Cross-cultural validation of the falls efficacy scale international (FES-I) in older people: results from Germany, the Netherlands and the UK were satisfactory. Disabil Rehabil 2007; 29: 155-62.

25. Freiberger E, Blank W, Salb J, et al.: Effects of a complex intervention on fall risk in the general practitioner setting: a cluster randomized controlled trial. Clin Interv Aging 2013; 8: 1-10.

26. Freiberger E, Haberle L, Spirduso WW, Rixt Zijlstra GA: Long-term effects of three multicomponent exercise interventions on physical performance and fall-related psychological outcomes in communitydwelling older adults: a randomized controlled trial. J Am Geriatr Soc 2012; 60: 437-46. 
27. Spice CL, Morotti W, George S, et al.: The Winchester falls project: a randomised controlled trial of secondary prevention of falls in older people. Age Ageing 2009; 38: 33-40.

28. Hadfield JD: MCMC Methods for Multi-Response Generalized Linear Mixed Models: The MCMC glmm R Package. J Stat Softw 2010; 33: $1-22$.

29. Lord SR, Ward JA, Williams P, Strudwick M: The effect of a 12-month exercise trial on balance, strength, and falls in older women: a randomized controlled trial. J Am Geriatr Soc 1995; 43: 1198-206.

30. Sherrington C, Whitney JC, Lord SR, et al.: Effective exercise for the prevention of falls: a systematic review and meta-analysis. J Am Geriatr Soc 2008; 56: 2234-43

31. Sherrington C, Tiedemann A, Fairhall N, Close JC, Lord SR: Exercise to prevent falls in older adults: an updated meta-analysis and best practice recommendations. N.SW Public Health Bull 2011; 22: 78-83.

32. Onder G, Penninx BW, Lapuerta P, et al.: Change in physical performance over time in older women: the women's health and aging study. J Gerontol A Biol Sci Med Sci 2002; 57: M289-93.

33. Nevitt MC, Cummings SR, Hudes ES: Risk factors for injurious falls: a prospective study. J Gerontol 1991; 46: M164-70.

\section{Corresponding autho}

Monika Siegrist, PhD

Lehrstuhl und Poliklinik für Präventive und Rehabilitative Sportmedizin

Technische Universität München

Georg-Brauchle-Ring 56-58

80992 München

siegrist@sport.med.tum.de
Q Supplementary material www.aerzteblatt-international.de/16m0365 


\section{Supplementary material to:}

\section{Fall Prevention in a Primary Care Setting}

The Effects of a Targeted Complex Exercise Intervention in a Cluster Randomized Trial

by Monika Siegrist, Ellen Freiberger, Barbara Geilhof, Johannes Salb, Christian Hentschke, Peter Landendoerfer, Klaus Linde, Martin Halle, and Wolfgang A. Blank

Dtsch Arztebl Int 2016; 113: 365-72. D0I: 10.3238/arztebl.2016.0365

\section{eBOX 1}

\section{Further information about secondary outcomes}

The Balance ability and mobility were assessed by the 'Timed-Up-and-Go-Test' (TUG). The participants were asked to stand up from a standard chair, walk a distance of three meters at a normal pace, turn, walk back to the chair and sit down $(20,22)$. A stopwatch was used to time the test (in seconds). Functional strength of the lower extremities and the dynamic balance capability were measured by the 'Chair-Stand-Test' (CST). The patients were asked to complete five rapid chair rise cycles from a standard chair and the time required for the test (in seconds) was documented. The static balance measurement (modified Romberg, mRomberg) was assessed using three measurements according to the 'Short Physical Performance Battery' with the participants' feet side by side, in semi-tandem, and full tandem position. The participant was asked to stand in each position for ten seconds. The total balance time in all three tests was used for comparison ( 0 to 30 seconds) (23) as previously described (18). Fear of falling was assessed with the German version of the Falls Efficacy Scale-International (FES-I) (24), comprising 16 questions on demanding activities in daily living ( $1=$ not at all concerned to 4 points = very concerned). To obtain the total score, the sum of points of all answers was calculated. Secondary endpoints were assessed by the general practitioners at baseline and after 12 months.

\section{eBOX 2}

\section{Further information on statistical analysis}

To take into account possible overdispersion in Poisson models, where the variance exceeds the mean parameter of the distribution, the generalized linear mixed effects Poisson model was fitted with Monte Carlo Markov Chain (MCMC) methods in a Bayesian setup. Mean and variance parameter estimates in the employed model can technically be viewed as random and were estimated separately. This is comparable to assume a negative binominal distribution which also estimates a separate variance parameter. We applied this method, because of its advantage to fit a model that accounts on the one hand for the clustered structure and on the other hand for overdispersion in count data. Because the number of returned falls diaries, collected monthly, differed between individuals, all analyses of numbers of falls were adjusted accordingly. Per considered secondary outcome measure (faller, fall-related injuries, TUG, CST, modified Romberg, FES-I) a three level linear mixed effects model for continuous normally distributed outcomes was determined for analysis with patients nested in general practices and measurements nested in patients and time and intervention group as crossed experimental factors with two measurement occasions and two groups. Analyses were based on available cases, missing values were not replaced. Data were analyzed with R environment for statistical computing (R Foundation for Statistical Computing, Vienna Austria) and SPSS (SPSS Inc., Chicago, II., USA). 


\section{eTABLE 1}

Further information about the PreFalls Intervention Program

\begin{tabular}{|c|c|c|c|c|c|}
\hline Main intervention components & $\begin{array}{c}\text { Month } \\
1\end{array}$ & $\begin{array}{l}\text { Month } \\
2\end{array}$ & $\begin{array}{c}\text { Month } \\
3\end{array}$ & $\begin{array}{c}\text { Month } \\
4\end{array}$ & Total \\
\hline Strength training $*^{1}$ & 2 & 2 & 1 & 1 & 6 \\
\hline Challenging balance training & 2 & 2 & 2 & 2 & 8 \\
\hline Functional training $*^{2}$ & & 1 & & & 1 \\
\hline Gait training & 1 & & 1 & & 2 \\
\hline Body awareness & & 1 & & 1 & 2 \\
\hline Fall risk education $*^{3}$ & & 1 & 2 & & 3 \\
\hline Heimtrainingsprogramm ** & 1 & & & 1 & 2 \\
\hline
\end{tabular}

${ }^{* 1}$ Progressive upper and lower body strength exercises and stretching exercises with increasing levels of difficulty

$\star^{2}$ Functional training included e.g. getting up from the floor after a fall

${ }^{*}$ Addressing misconceptions about fall risk, attitudes about falls, thoughts and concerns about falling, negative and positive thinking patterns, and potential environmental fall hazards

${ }^{*}$ Training manual describing safe home exercises

The exercises were performed mostly in the standing position without additional equipment. After four weeks the patients were asked to add an unsupervised session per week (12 sessions in all) according to a booklet with written information and images on how to perform the exercise at home, as well as safety issues.

\section{GTABLE 2}

Fall-related injuries

\begin{tabular}{l|c|c} 
& $\begin{array}{c}\text { Intervention group } \\
(\mathrm{N}=222)\end{array}$ & $\begin{array}{c}\text { Control group } \\
(\mathrm{N}=156)\end{array}$ \\
\hline Fracture & $2.9 \%(\mathrm{n}=7)$ & $4.1 \%(\mathrm{n}=10)$ \\
\hline Concussion & $0.4 \%(\mathrm{n}=1)$ & $0 \%(\mathrm{n}=0)$ \\
\hline Abrasions & $4.6 \%(\mathrm{n}=11)$ & $6.6 \%(\mathrm{n}=16)$ \\
\hline Lacerations & $5.5 \%(\mathrm{n}=13)$ & $4.1 \%(\mathrm{n}=10)$ \\
\hline Contusions & $26.9 \% \quad(\mathrm{n}=64)$ & $24.4 \%(\mathrm{n}=59)$ \\
\hline Other injuries (e.g. meniscus injury) & $2.1 \%(\mathrm{n}=5)$ & $0.4 \%(\mathrm{n}=1)$ \\
\hline
\end{tabular}

